\title{
Diagnosis and treatment of dementia: 1. Risk assessment and primary prevention of Alzheimer disease
}

\author{
Christopher Patterson MD, John W. Feightner MD MSc, Angeles Garcia MD PhD, \\ G.-Y. Robin Hsiung MD MHSc, Christopher MacKnight MD MSc, A. Dessa Sadovnick PhD
}

\section{ABSTRACT}

Background: In addition to nonmodifiable genetic risk factors, potentially modifiable factors such as hypertension, hyperlipidemia and environmental exposures have been identified as risk factors for Alzheimer disease. In this article, we provide physicians with practical guidance on risk assessment and primary prevention of Alzheimer disease based on recommendations from the Third Canadian Consensus Conference on the Diagnosis and Treatment of Dementia, held in March 2006.

Methods: We developed evidence-based guidelines using systematic literature searches, with specific criteria for study selection and quality assessment, and a clear and transparent decision-making process. We selected studies published from January 1996 to December 2005 that met the following criteria: dementia (all-cause, Alzheimer disease or vascular dementia) as the outcome; longitudinal cohort study; study population broadly reflective of Canadian demographics; and genetic risk factors and general risk factors (e.g., hypertension, education, occupation and chemical exposure) identified. We graded the strength of evidence using the criteria of the Canadian Task Force on Preventive Health Care.

Results: Of 3424 articles on potentially modifiable risk factors for dementia, 1719 met our inclusion criteria; 6o were deemed to be of good or fair quality. Of 1721 articles on genetic risk factors, 62 that met our inclusion criteria were deemed to be of good or fair quality. On the basis of evidence from these articles, we made recommendations for the risk assessment and primary prevention of Alzheimer disease. For the primary prevention of Alzheimer's disease, there is good evidence for controlling vascular risk factors, especially hypertension (grade A), and weak or insufficient evidence for manipulation of lifestyle factors and prescribing of medications (grade C). There is good evidence to avoid estrogens and high-dose ( $>400 \mathrm{IU} / \mathrm{d}$ ) of vitamin $\mathrm{E}$ for this purpose (grade E). Genetic counselling and testing may be offered to at-risk individuals with an apparent autosomal dominant inheritance (grade B). Screening for the apolipoprotein E genotype in asymptomatic individuals in the general population is not recommended (grade E).
Interpretation: Despite the personal and societal burden of dementia, our understanding of genetic predisposition to dementias and the contribution of other risk factors remains limited. More importantly, there are few data to explain the overall risks and benefits of prevention strategies or their impact of risk modification.

Une version française de ce résumé est disponible à l'adresse www.cmaj.ca/cgi/content/full/178/5/548/DCI

$$
\text { CMAJ 2008;178(5):548-56 }
$$

\section{The case}

Mr. A, a 45-year-old professional, presents for a routine health check-up, during which he states "I am quite worried about getting Alzheimer disease, just like my mother." He goes on to say "As you know, our family has been caring for her while she slowly deteriorated. A month ago, we had to move her to a long-term care facility. It is really taking a toll on our family. So I want to know what my chances are of escaping this terrible disease. I want to do everything I can to avoid my mother's fate." Mr. A then goes on to say that his mother, who is alive, had her first symptoms of dementia at the age of 74 years. To his knowledge, no other family members, including aunts and uncles, have been affected by dementia. Mr. A is relatively healthy. He has never smoked and rarely drinks alcohol. However, he has been taking medication for hypertension for over a year and has hyperlipi-

From the Division of Geriatric Medicine (Patterson), McMaster University, Hamilton, Ont.; the Department of Family Medicine (Feightner), University of Western Ontario, London, Ont.; the Department of Medicine (Garcia), Queen's University, Kingston, Ont.; the Departments of Medicine (Hsiung, Sadovnick) and Medical Genetics (Sadovnick), University of British Columbia, Vancouver, BC; and the Department of Medicine (MacKnight), Dalhousie University, Halifax, NS

This series is based on recommendations from the Third Canadian Consensus Conference on the Diagnosis and Treatment of Dementia.

Series editor: Howard Chertkow MD, Department of Neurology, McGill University and the Bloomfield Centre for Research in Aging, Lady Davis Institute, Sir Mortimer B. Davis-Jewish General Hospital, Montréal, Que. 
demia. On this visit, his blood pressure is $145 / 90 \mathrm{~mm} \mathrm{Hg}$. His total cholesterol level is $5.7 \mathrm{mmol} / \mathrm{L}$, high-density lipoprotein (HDL) cholesterol level $1.39 \mathrm{mmol} / \mathrm{L}$, low-density lipoprotein cholesterol level $4.31 \mathrm{mmol} / \mathrm{L}$, triglyceride level $2.34 \mathrm{mmol} / \mathrm{L}$ and total cholesterol:HDL ratio 4.1.

What should you advise Mr. A about his risk of dementia? More importantly, what should you tell him about preventing or decreasing his chances of getting dementia?

$\mathrm{T}$ his hypothetical patient's story and concerns are all too familiar. Dementia is a devastating illness for patients. For families, the emotional, physical and financial burden of this illness is also substantial. Because $\mathrm{I}$ in I2 Canadians over the age of 65 years may be affected by dementia, ${ }^{1}$ there are also important consequences for society as a whole.

Why does dementia occur in some people and not others? How can patients minimize their chances of facing a future with dementia? In recent years, a number of longitudinal studies have better defined risk factors for various types of dementia. ${ }^{2}$ Lifestyle factors such as tobacco use, diet and alcohol as well as vascular risk factors have emerged as important predictors. Several genetic factors have also been identified. ${ }^{3}$ In this article, we provide physicians with practical guidance on risk assessment and primary prevention of Alzheimer disease supported by evidence-based recommendations from the Third Canadian Consensus Conference on the Diagnosis and Treatment of Dementia (Box I). A description of the process used to generate these recommendations is provided in the first article of this series ${ }^{1}$ and in an online appendix accompanying this article (available at www.cmaj.ca/cgi /content/full/178/5/548/DC2).

\section{Approach to risk assessment}

Like Mr. A, many patients ask about their baseline risk of dementia. Family physicians should appreciate that they are attempting to predict the onset of a heterogeneous group of diseases. As a consequence, it is possible that some risk factors may predispose to some types of dementia while having little influence on predicting the onset of other types. In this article we focus on Alzheimer disease, first considering genetic aspects, then vascular, lifestyle and finally sociodemographic risk factors (Table I).

\section{Genetic risk factors}

To assess genetic risk in an individual or family, it is critical to obtain an accurate family history with as much information as possible about the diagnosis of dementia and age of onset in reportedly affected family members. Obtaining reliable answers to these questions is not a trivial task. If it is not possible to examine the affected family members, confirmation of diagnosis by review of clinical reports and neuropathologic findings, if available, adds to diagnostic certainty. In addition to confirming the diagnosis in relatives, attempting to establish the age of onset is also important. Often the medical history of a person's parents is unknown because of distance, life circumstance such as divorce, reticence of the previous generation to discuss personal issues, or death from other causes at a young age. Furthermore, the person may have no siblings, or have no information on siblings' health status. Incomplete family histories can be a major hurdle in assessing genetic risk.

Early-onset Alzheimer disease, which may have a significant genetic component, is generally defined as occurring before 60 years of age. It accounts for only $6 \%-7 \%$ of all cases of Alzheimer disease. ${ }^{19,20}$ From this small pool of patients, only I3\% clearly exhibit autosomal dominant transmission over more than one generation, which means that a sibling, a parent and a grandparent also has Alzheimer disease. ${ }^{20,21}$ To date, all 3 known causative gene mutations (changes that almost always result in Alzheimer disease if the patient lives long enough) lead to the early-onset form. ${ }^{3}$ The first of these genes to be identified was the amyloid precursor protein gene, located on chromosome 2I. Mutations in this gene cause excessive cleavage by the $\beta$ - and $\gamma$-secretase enzymes, instead of normal cleavage by the $\alpha$-secretase enzyme. The result is increased production of toxic $\beta$-amyloid fragments, which are converted into insoluble aggregates that form senile plaques in brain tissue (Figure I and Figure 2). Two other genes that cause familial early-onset Alzheimer's disease are presenilin-I, located on chromosome I4, and presenilin-2, located on chromosome I. Both of these genes are involved in the $\gamma$-secretase complex, and mutations lead to excessive cleavage by the $\gamma$ secretase enzyme, which results in increased production and accumulation of $\beta$-amyloid fragments (Figure I). These mechanisms are not known to be associated with late-onset or sporadic Alzheimer disease.

Table 1: Risk factors for Alzheimer disease

\begin{tabular}{|c|c|}
\hline Factor & Risk $(95 \% \mathrm{Cl})$ \\
\hline Systolic hypertension > $160 \mathrm{~mm} / \mathrm{Hg}$ & $\begin{array}{l}\text { RR: } 1.5(1.0-2.3)^{4} \\
\text { OR: } 2.3(1.0-5.5)^{5}\end{array}$ \\
\hline Serum cholesterol $>6.5 \mathrm{mmol} / \mathrm{L}$ & $\begin{array}{l}\text { RR: } 2.1(1.0-4.4)^{5} \\
\text { RR: } 3.1(1.2-8.5)^{6}\end{array}$ \\
\hline $\begin{array}{l}\text { Moderate wine consumption } \\
(250-500 \mathrm{~mL} / \mathrm{d}) \text { compared with more } \\
\text { or less than this amount }\end{array}$ & RR: $0.53(0.3-0.95)^{7}$ \\
\hline $\begin{array}{l}\text { High level of physical activity* } \\
\text { compared with little or no regular } \\
\text { exercise }\end{array}$ & $\begin{array}{l}\text { RR: } 0.5(0.28-0.90)^{8} \\
\text { RR: } 0.55(0.34-0.88)^{9} \\
\text { RR: } 0.69(0.5-0.96)^{10}\end{array}$ \\
\hline Smoking, current & $\begin{array}{l}\text { RR: } 1.74(1.21-2.50)^{11} \\
\text { RR: } 1.99(1.33-2.98)^{12}\end{array}$ \\
\hline \multicolumn{2}{|l|}{ Head injury, with loss of consciousness } \\
\hline Moderate & HR: $2.32(1.04-5.1)^{13}$ \\
\hline Severe & HR: $4.51(1.77-11.47)^{13}$ \\
\hline Education > $15 \mathrm{yr}(\mathrm{v} .<12 \mathrm{yr})$ & RR: $0.48(0.27-0.84)^{14}$ \\
\hline Statin drugs & $\begin{array}{l}\text { RR: } 0.82(0.46-1.46)^{15} \\
\text { HR: } 1.19(0.35-2.96)^{16}\end{array}$ \\
\hline Nonsteroidal anti-inflammatory drugs & $\begin{array}{l}\text { RR: } 0.42(0.26-0.66)^{17} \\
\text { RR: } 0.51(0.37-0.70)^{18}\end{array}$ \\
\hline
\end{tabular}

Note: $\mathrm{Cl}=$ confidence interval, $\mathrm{RR}=$ relative risk, $\mathrm{OR}=$ odds ratio, $\mathrm{HR}=$ hazard ratio.

*See section on lifestyle factors for details about physical activity. 
Box 1: Recommendations for the assessment and management of risk factors for, and the primary prevention of, Alzheimer disease*

\section{Genetic risk factors}

1. Predictive genetic testing, with appropriate pre-and post-testing counselling, may be offered to the following at-risk individuals with an apparent autosomal dominant inheritance when a family-specific mutation has been identified [grade B recommendation, level 2 evidence; new recommendation]

a. First-degree relatives (e.g., children and siblings) of an affected person with the mutation

b. First cousins of an affected person if the common ancestors (parents who were siblings) died before the average age of onset of dementia in the family

c. Nieces and nephews of an affected person whose parent (sibling of the affected person) died before the average age of onset of dementia in the family

d. Minors are not usually referred for predictive genetic testing in Canada, but occasionally such testing may be considered on a case-by-case basis by the relevant medical ethics committee(s) $\dagger$

2. Genetic screening for the apolipoprotein $E(A P O E)$ genotype in asymptomatic individuals in the general population is not recommended because of the low specificity and sensitivity [grade E recommendation, level 2 evidence; revised recommendation]. Note: This is also true of other putative susceptibility genes such as the sortilin-related receptor 1 gene (SORL1).

\section{Vascular risk factors}

1. There is good evidence to treat systolic hypertension ( $>160 \mathrm{~mm} \mathrm{Hg}$ ) in older individuals (age > 60 years). In addition to reducing the risk of stroke, the incidence of dementia may be reduced. The target systolic blood pressure should be $\leq 140 \mathrm{~mm} \mathrm{Hg}$ [grade A recommendation, level 1 evidence; new recommendation].

2. Although acetylsalicylic acid and statin therapy following myocardial infarction, antithrombotic therapy for nonvalvular atrial fibrillation, and correction of carotid artery stenosis $>60 \%$ have been shown to reduce the risk of stroke, there is insufficient evidence to recommend for or against these measures for the specific purpose of reducing the risk of dementia [grade $C$ recommendation, level 1 evidence; revised recommendation]

3. Although there are many reasons for treating type 2 diabetes mellitus, hyperlipidemia and hyperhomocysteinemia, there is insufficient evidence to recommend for or against treatment of these conditions for the specific purpose of reducing the risk of dementia [grade $\mathrm{C}$ recommendation, level 2 evidence; revised recommendation]

\section{Lifestyle risk factors}

1. Although there is insufficient evidence to make a firm recommendation for the primary prevention of dementia, physicians may advocate for strategies, including legislation, to reduce the risk of serious head injuries [grade $C$ recommendation, level 2 evidence; new recommendation]

2. Although there is insufficient evidence to make a firm recommendation for the primary prevention of dementia, physicians may advise their patients about, and advocate for, the wearing of appropriate protective clothing during the administration of pesticides, fumigants, fertilizers and defoliants [grade $C$ recommendation, level 2 evidence; new recommendation]

3. Although recommendations may be made on other grounds (e.g., as part of a healthy lifestyle), there is insufficient evidence to recommend for or against higher levels of physical or mental activity for the specific purpose of reducing the risk of dementia [grade $\mathrm{C}$ recommendation, level 2 evidence; new recommendation]

4. Although there is insufficient evidence to make a firm recommendation for the primary prevention of dementia, physicians may advocate for appropriate levels of education and strategies to retain students in appropriate learning environments [grade $\mathrm{C}$ recommendation, level 2 evidence; new recommendation]

5. Although there is insufficient evidence to make a firm recommendation for the primary prevention of dementia, physicians may choose to advise their patients about the potential advantages of increased consumption of fish, reduced consumption of dietary fat and moderate consumption of wine [grade $\mathrm{C}$ recommendation, level 2 evidence; new recommendation]

\section{Medications}

1. There is insufficient evidence to recommend for or against the prescription of nonsteroidal anti-inflammatory drugs for the sole purpose of reducing the risk of dementia [grade $\mathrm{C}$ recommendation, level 2 evidence; new recommendation]

2. There is good evidence to avoid the use of estrogen, alone or in combination with progesterone, for the sole purpose of reducing the risk of dementia [grade E recommendation, level 1 evidence; new recommendation]

3. There is insufficient evidence to recommend for or against supplementation with vitamins $E$ or $C$ for the prevention of dementia [grade C recommendation, level 2 evidence). High-dose vitamin $E$ ( $\geq 400 \mathrm{IU} / \mathrm{d}$ ) is associated with excess mortality and should not be recommended [grade E recommendation, level 1 evidence; new recommendation]

*Based on recommendations from the Third Canadian Consensus Conference on Diagnosis and Treatment of Dementia, held in March 2006. †Prenatal diagnostic testing is not offered in Canada. 
Among families in which causal genetic mutations for early-onset Alzheimer disease have been identified, 30\%$70 \%$ of mutations are in the presenilin-I gene, $10 \%-15 \%$ are in the amyloid precursor protein gene, and less than $5 \%$ are in the presenilin-2 gene. ${ }^{23}$ Many cases of early-onset Alzheimer disease do not have an identified genetic mutation, possibly because the specific genes have not yet been identified or because some cases may have different causes.

To date, no single causal genetic mutation has been identified for late-onset Alzheimer disease. Most cases are believed to be complex and likely influenced by a mixture of genetic risk factors (e.g., the apolipoprotein E gene $[A P O E]$ and the sortilin-related receptor I gene [SORLI]) and by acquired risk factors such as hypertension and diabetes, and probably many other factors yet to be defined. The risk to a person who has a first-degree relative (parent or sibling) with late-onset Alzheimer disease is slightly higher than the risk in the general population but much lower than the risk to someone with a familial pedigree of early-onset disease (see "Risk estimation" on page 554).

For late-onset Alzheimer disease, several genes have been implicated as risk factors. These genes increase the probability of, but do not guarantee the development of, Alzheimer disease. However, their absence does not guarantee that Alzheimer dis- ease will not develop. Currently only APOE has been confirmed as a genetic risk factor in multiple large, population-based studies. ${ }^{3}$ The $A P O E$ gene has 3 common allele forms: $\varepsilon 2$ (which occurs in $8 \%$ of white populations), $\varepsilon_{4}$ (in $15 \%$ ) and $\varepsilon_{3}$ (in about $75 \%$ ). The association of the $\varepsilon_{4}$ allele with late-onset Alzheimer disease is well established (Table 2). APOE is involved in cholesterol transport and $\beta$-amyloid formation, but its exact mechanism in promoting Alzheimer disease is unclear. ${ }^{24}$

The strength of the association between the APOE $\varepsilon 4$ allele and Alzheimer disease is stronger among women than among men. It also diminishes with age, being stronger among people between 55 and 65 years old and less so among older people. This is likely because the risk of Alzheimer disease rises sharply in older age, whether or not the $\varepsilon_{4}$ allele is present. Given the uncertainties surrounding potential increased risk for Alzheimer disease in an individual rather than in a population, screening for the APOE genotype is not recommended for clinically asymptomatic people as part of routine clinical practice.

Recently, the sortilin-related receptor gene (SORLI) has been associated with late-onset Alzheimer's disease in several populations of different ethnic backgrounds in the United States. ${ }^{25,26}$ SORLI is involved in amyloid precursor protein processing, which adds further support to the role of the

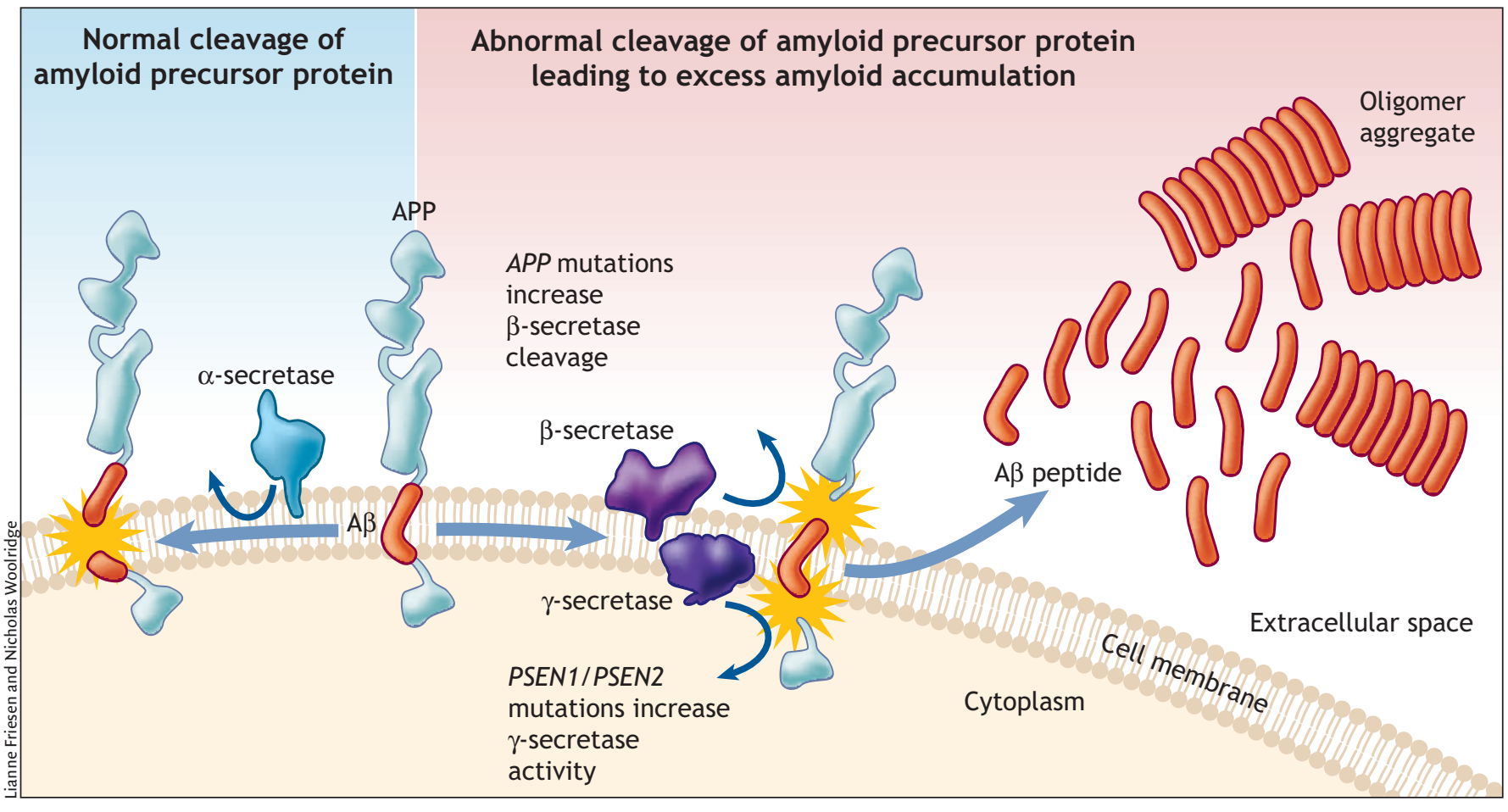

Figure 1: The amyloid precursor protein (APP) is a transmembrane protein that can undergo a series of proteolytic cleavage by secretase enzymes. When it is cleaved by $\alpha$-secretase in the middle of the $\beta$-amyloid domain (A $\beta$ ), it is not amyloidogenic. However, when APP is cleaved by $\beta$ - and $\gamma$-secretase enzymes, neurotoxic $A \beta$ peptides are released, which can accumulate into oligomer aggregate. Mutations in the APP gene tend to inhibit cleavage by $\alpha$-secretase and consequently enable preferential cleavage by $\beta$-secretase. Mutations in the presenilin-1 and presenilin-2 genes (PSEN1 and PSEN2), which are components of the $\gamma$-secretase complex, increase cleavage by $\gamma$-secretase at this site. In both situations, the result is excess $A \beta$ peptide production. The current $A \beta$ hypothesis suggests that the soluble oligomers can impair synaptic function between neurons. Simultaneously, the oligomers may aggregate into insoluble $\beta$-sheet amyloid fibrils, which can trigger a local inflammatory response. ${ }^{22}$ Over time, the subsequent oxidative stress and biochemical changes ultimately lead to neuronal death and the development of neuritic plaques typical of Alzheimer disease. 
amyloid cascade in the pathogenesis of Alzheimer disease. The utility of SORLI in clinical risk assessment has yet to be determined, and testing for this gene is not yet available.

Although it is relatively straightforward to distinguish early-onset from late-onset Alzheimer disease when the age of onset is well below 60 or well above 65 years, there is ambiguity when the illness begins between 60 and 65 years, and a clear distinction between the 2 conditions is not always possible. There are well-documented cases of Alzheimer disease with proven pathogenic mutations in which symptoms first

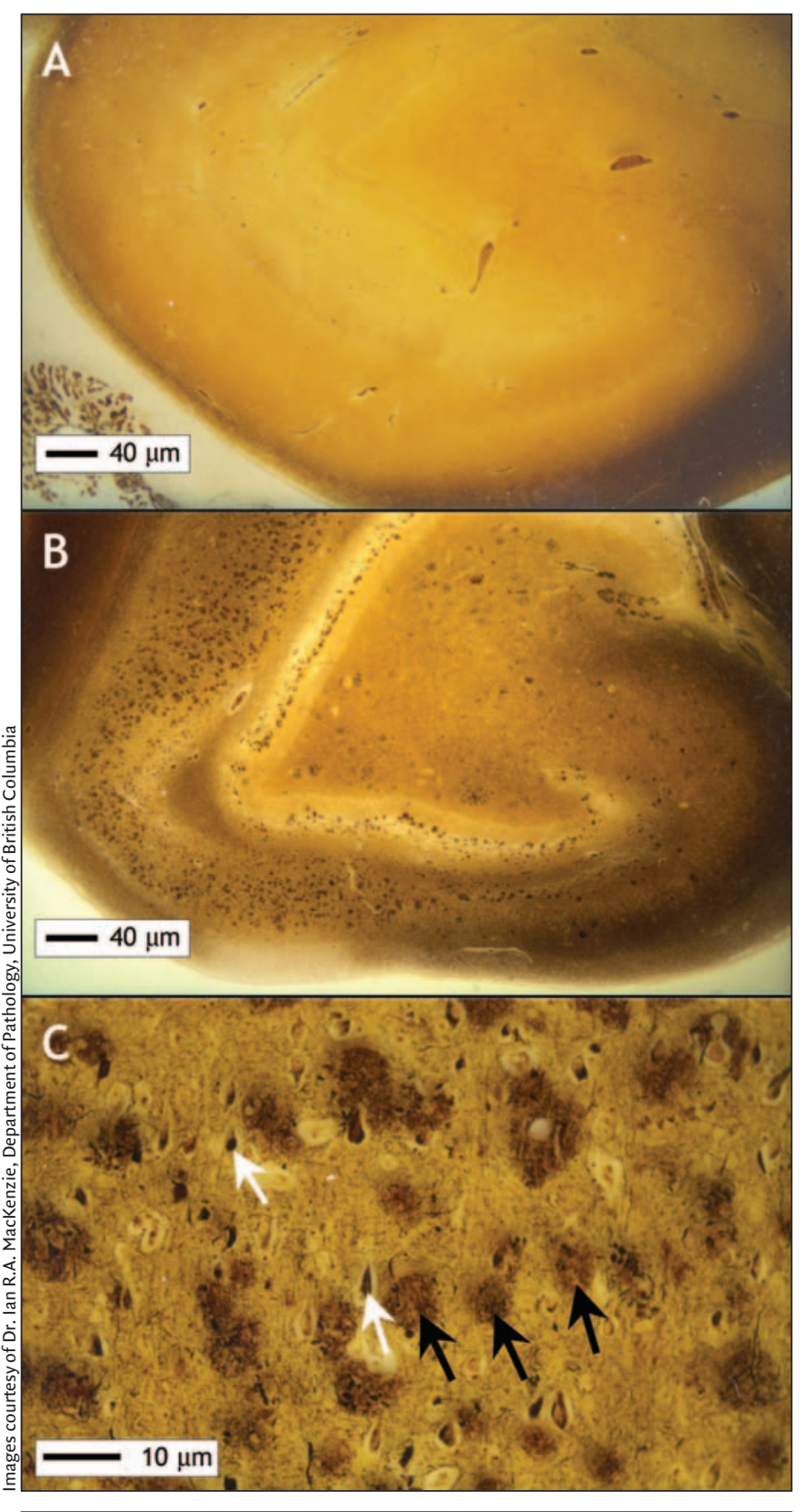

Figure 2: Images of normal hippocampus (A) and hippocampus of a patient with Alzheimer disease (B) [Bielschowsky stain]. The numerous dark brown spots seen in the abnormal hippocampus are the neuritic plaques typical of Alzheimer disease. At higher magnification (C), these plaques (black arrows) and tangles (white arrows) seen in Alzheimer disease are clearly visible. appeared after 65 years of age in some familial pedigrees of early-onset disease. ${ }^{27-30}$ Early-onset Alzheimer disease and familial Alzheimer disease are not synonymous. Sporadic cases of early-onset Alzheimer disease can occur with no family history and no genetic mutations, and familial late-onset pedigrees can occur with no responsible genes identified. ${ }^{31-33}$

A strong family history of dementia should trigger further investigation and referral to a specialist for consultation (Box 2). All patients suspected of having familial early-onset Alzheimer disease should be referred to a specialty memory clinic or genetic clinic for further evaluation (a list of Canadian centres offering clinical genetic services is available at http://ccmg.medical.org/clinical.html).

Before any testing is performed, genetic counselling is considered essential. The discovery of an inherited causative gene for Alzheimer disease is likely to be extremely distressing. Thus, genetic testing should not take place unless all of the potential risks and benefits have been clearly explained and considered.

To help determine whether there is a causative gene in Mr. A's family, we must consider 2 important questions. First, at what age did Mr. A's mother first experience symptoms of Alzheimer disease? Second, do any of his other family members have dementia and, if so, at what age was the onset and how are they related to Mr. A? In this instance, Mr. A appears to be a reliable informant about his mother's health history. There is nothing in Mr. A's reported family history to suggest autosomal dominant multi-generational transmission. Therefore, Mr. A needs no further work-up or assessment for the genetic aspect of his risk assessment.

\section{Nongenetic risk factors}

\section{Vascular risk factors}

Considerable evidence from longitudinal cohort studies has indicated that the relation between blood pressure and subsequent development of dementia is somewhat complex. ${ }^{2} \mathrm{Al}-$ though a number of studies have shown that elevated systolic blood pressure is associated with an increased risk of both Alzheimer disease and all-cause dementia, curiously some studies have shown that a systolic blood pressure below I40 $\mathrm{mm} \mathrm{Hg}$ is also associated with an increased risk. ${ }^{4}$ Notwithstanding these and other apparently contradictory findings, the results of the Systolic Hypertension in Europe (SYST-EUR) study revealed a reduced risk of dementia among participants receiving antihypertensive treatment. ${ }^{34}$ In this trial, more than 3000 patients over 60 years old who had systolic blood pressures of 160-219 $\mathrm{mm} \mathrm{Hg}$ and diastolic pressures below $95 \mathrm{~mm}$ $\mathrm{Hg}$, measured while seated, were randomly assigned to receive either nitrendipine (1o-40 mg/d), with added enalapril or hydrochlorothiazide, titrated to reduce the blood pressure by at least $20 \mathrm{~mm} \mathrm{Hg}$ to reach a value below $150 \mathrm{~mm} \mathrm{Hg}$, or matching placebo. ${ }^{34}$ The participants were free of dementia at baseline and were subsequently monitored by means of the MiniMental State Examination ${ }^{35}$ and further diagnostic tests to reach a definitive diagnosis of dementia (according to the criteria of the Diagnostic and Statistical Manual of Mental Disorders, third edition, revised [DSM-III-R]) if the score fell below 
23. After a median follow-up of 2 years, the incidence of dementia was reduced by $50 \%$, from 7.7 to 3.8 cases per 1000 patient-years in the treatment group, an absolute risk reduction of $0.39 \%$. The relative risk of dementia was 0.47 ( $95 \%$ confidence interval [CI] $0.28-0.78$ ), and most cases were diagnosed as probable Alzheimer disease. In absolute terms, the number of cases of hypertension needed to treat for 5 years to prevent I case of dementia is about 53 . No other randomized controlled trial has shown such convincing results, and a metaanalysis of 4 trials concluded that the relative risk for dementia after treatment of hypertension was 0.80 (95\% CI 0.63-I.02), just missing statistical significance. ${ }^{36}$ In the case of Mr. A, depending on the severity of his hypertension, appropriate treatment will reduce his risk of stroke, heart failure and myocardial infarction. Although there is no definitive evidence in his age group, his risk of dementia may also be reduced.

Epidemiologic studies have established an association between hyperlipidemia and subsequent development of dementia. Longitudinal studies have established that midlife elevation of the total serum cholesterol level is associated with an increased risk of subsequent Alzheimer disease (relative risk 2.I-3.I.). ${ }^{2}$ However, 2 large randomized controlled trials failed to show that use of 3-hydroxy-3-methylglutaryl-coenzyme A (HMG-CoA) reductase inhibitors (statins) reduced the incidence of dementia. One trial compared pravastatin $(40 \mathrm{mg} / \mathrm{d})$ with placebo in nearly 6000 men and women aged $70-80$ years who had a baseline total cholesterol level of $4.0-9.0 \mathrm{mmol} / \mathrm{L}$; the mean duration of follow-up was 3.2 years. ${ }^{37}$ By the end of the trial, there were no significant differences in the MiniMental State Examination scores between the pravastatin and placebo groups (mean difference 0.06 [out of 30], 95\% CI $0.04-0.16 ; p=0.59$ ). Neither was there any difference in scores on instrumental activities of daily living, a sensitive marker for dementia. The other study compared simvastatin $(40 \mathrm{mg} / \mathrm{d})$ with placebo in over 20000 men and women aged $40-80$ years who had a baseline total cholesterol level greater than $3.5 \mathrm{mmol} / \mathrm{L}$ and who were followed for 5 years. ${ }^{38}$ By the end of the trial, the incidence of dementia was $0.3 \%$ in each of the 2 groups.

Although there may be compelling reasons to treat hyperlipidemia in Mr. A, especially if he had additional risk factors such as smoking, and a strong family history of premature vascular disease, there is no evidence that treatment of hyperlipidemia will reduce his risk of subsequent Alzheimer disease. ${ }^{39}$

Table 2: Risk of Alzheimer disease by apolipoprotein $\mathrm{E}$ genotype $^{3}$

\begin{tabular}{lc}
\hline Genotype & Odds ratio $(95 \% \mathrm{CI})^{*}$ \\
\hline$\varepsilon 3 / \varepsilon 3$ & $1.0[$ ref] \\
Single $\varepsilon 4$ & $3.2(2.9-3.5)$ \\
$\varepsilon 4 / \varepsilon 4$ & $11.6(8.9-15.4)$ \\
$\varepsilon 2 / \varepsilon 3$ & $0.6(0.5-0.8)$ \\
\hline
\end{tabular}

Note: $\mathrm{Cl}=$ confidence interval, ref = reference group.

*Compared with white people, the strength of the association is weaker among

black and Hispanic people and stronger among people of Japanese descent.

The association is stronger among women than among men.
Box 2: Asymptomatic people at high risk for familial Alzheimer disease for whom genetic testing may be considered

- Child of a person in whom a causative mutation has been identified

- Sibling of a person in whom a causative mutation has been identified, especially if the sibling is younger than the affected person was at the age of dementia onset

- Niece or nephew of a person in whom a causative mutation has been identified and whose parent (sibling of the affected person) died before the age of onset of disease in the affected person

- Minors are not usually referred for predictive genetic testing in Canada, but occasionally such testing may be considered on a case-by-case basis by the relevant medical ethics committee(s)*

*Prenatal diagnostic testing is not offered in Canada.

\section{Lifestyle factors}

For Mr. A, and indeed for all healthy middle-aged and elderly patients worried about memory loss, a pressing issue is whether there are lifestyle factors that could (or should) be modified in an attempt to preserve memory function with aging. Although a "healthy lifestyle" in general can be recommended to all patients, the question is whether there is an evidence base to support specific recommendations to Mr. A in order to preserve his memory.

Early case-control studies had suggested that tobacco smoking actually reduced the risk of dementia, but longitudinal cohort studies have identified a significantly increased risk of all-cause dementia and Alzheimer disease among tobacco smokers. ${ }^{12}$ A pooled analysis of results from 4 European population-based studies involving over 28 ooo people concluded that current smokers, but not former smokers, were at increased risk for Alzheimer disease. ${ }^{11}$ Although there is no conclusive evidence that smoking cessation will lessen his risk of Alzheimer disease, the mere possibility provides yet another reason to discourage Mr. A from smoking.

Both total dietary fat intake and reduced levels of omega 3 fatty acids have been linked to an increased risk of dementia in epidemiologic studies. ${ }^{40} \mathrm{~A}$ recent longitudinal study has also suggested that adherence to a Mediterranean-style diet is associated with a decreased risk of Alzheimer disease,${ }^{41}$ as is consumption of fish. ${ }^{2}$ In the absence of evidence from randomized controlled trials, we cannot offer unequivocal advice regarding diet for the primary prevention of dementia. However, in Mr. A's case, the presence of hyperlipidemia mandates that counselling to reduce intake of both saturated and total dietary fat should constitute part of his overall management regardless of any potential impact on his risk of dementia.

Increased levels of physical activity have been linked to a reduced risk of subsequent dementia. Data from the Canadian Study of Health and Aging have associated regular physical activity (defined by a simple "yes/no" question) with a reduced risk of Alzheimer disease (relative risk o.69, 95\% CI 0.50-0.96). ${ }^{10} \mathrm{In}$ another analysis of the data from this study, the level of physical activity was assessed by combining 2 questions regarding fre- 
quency and intensity of exercise for participants who reported regular physical activity. A high level of exercise was defined as 3 or more times weekly at an intensity greater than walking. When compared with those who reported no regular exercise, those reporting a high level of exercise had a decreased risk of Alzheimer disease developing in 5 years (odds ratio $0.50,95 \%$ CI 0.28 $0.90) .^{8}$ In the Cardiovascular Health Study, conducted in the United States, participants who expended the highest quartile of energy (calculated at more than $1657 \mathrm{kcal} / \mathrm{wk}$ ) had a lower risk of all-cause dementia (adjusted relative risk $0.58,95 \% \mathrm{CI} 0.4 \mathrm{I}-$ 0.83 ) and of Alzheimer disease (adjusted relative risk 0.55, 95\% CI $0.34-0.88$ ) compared with participants who expended the lowest quartile of energy (estimated at less than $248 \mathrm{kcal} / \mathrm{wk}$ ). ${ }^{9}$ In Mr. A's case, even in the absence of evidence from randomized controlled trials on this topic, it is reasonable to recommend regular physical activity given his stated risk factors.

Intellectually challenging activity of various types has been associated with a reduced risk of dementia in longitudinal studies. Daily mental activities were associated with a decreased risk of all-cause dementia (relative risk 0.59) in the Kungsholmen study. ${ }^{42}$ Similarly, the Washington Heights Study (New York) showed a reduced risk of all-cause dementia (relative risk o.62) among participants who engaged in a higher level of leisure activity (self-reported participation in $>6$ of $\mathrm{I}_{3}$ activities $\mathrm{v}$. $<6 \mathrm{ac}-$ tivities [low level] in the previous month) ${ }^{43}$ There is emerging evidence that cognitive training, especially involving novel or unfamiliar tasks, may delay cognitive decline. A recently published follow-up study of a randomized controlled trial of cognitive training appeared to show sustained improvement in specific cognitive performance up to 5 years after the intervention. ${ }^{44}$ Whether this type of endeavour translates into a reduced risk of dementia remains to be proven.

Epidemiologic evidence has established that moderate consumption of wine (250-500 mL/d), compared with an intake of more or less than this amount, is associated with a reduced risk of subsequent all-cause dementia (relative risk $0.56,95 \% \mathrm{CI}$ $0.36-0.92$ ) and of Alzheimer disease (relative risk $0.53,95 \% \mathrm{CI}$ $0.30-0.95)^{7}$ Advice about alcohol consumption should be tempered by the known risks of excessive use in terms of neurologic and other organ damage, as well as increased risk of injury from intoxication. In the absence of evidence from randomized controlled trials, a firm recommendation for the use of alcohol to reduce the risk of Alzheimer disease cannot be offered, neither can we recommend that a nondrinker begin to drink alcohol.

There has been controversy in the literature concerning the contribution of head injury to subsequent development of dementia. Long-term follow-up of a cohort of World War II US Navy and Marine servicemen who were admitted to hospital during military service has shed light on this issue. Those who were admitted with moderate or severe head injury with loss of consciousness experienced an increased risk of subsequent Alzheimer disease (hazard ratio 2.32, 95\% CI I.04-5.17, for moderate head injury and 4.5I, 95\% CI I.77-II.47, for severe head injury) compared with those admitted because of other causes. ${ }^{13}$ It is therefore appropriate to encourage Mr. A to wear appropriate head protection should he engage in contact sports or in activities that could result in head injuries such as bicycling.

\section{Sociodemographic risk factors}

There is evidence from longitudinal cohort studies that the risk of Alzheimer disease is increased among people who have received shorter periods of education. For example, in an American longitudinal cohort study, participants who had more than I5 years of education had a reduced risk of Alzheimer disease (relative risk $0.48,95 \% \mathrm{CI}$ 0.27-0.84) when compared with those who had less than 12 years of education. ${ }^{14}$ Although studies of occupation and dementia risk are inconclusive, a longitudinal study from Manitoba showed that occupational exposure to environmental toxins such as pesticides, fertilizers, fumigants and defoliants was associated with an increased risk of Alzheimer disease (relative risk 4.35, 95\% CI I.05-17.90). ${ }^{45}$

\section{Risk estimation}

A 20-year follow-up analysis of the Cardiovascular Risk Factor, Aging and Dementia (CAIDE) study population in Scandinavia was recently published. ${ }^{46}$ Data on midlife risk factors were entered into a logistic regression model, with dementia as the outcome, and a simple scoring system was devised. Two models were proposed: one included $A P O E$ status, but its inclusion did not increase the accuracy of the predictive model. The scoring system and risk of late-onset dementia are shown in Table 3 and Table 4. For Mr. A, if he is physically inactive, has a systolic

Table 3: Logistic regression model for dementia risk in 20 years, based on scores for midlife risk factors*

\begin{tabular}{|c|c|c|}
\hline Risk factor & Odds ratio $(95 \% \mathrm{Cl})$ & Score \\
\hline \multicolumn{3}{|l|}{ Age, yr } \\
\hline$<47$ & 1 [ref] & 0 \\
\hline $47-53$ & $2.958(1.261-6.938)$ & 3 \\
\hline$>53$ & $5.825(2.192-15.476)$ & 4 \\
\hline \multicolumn{3}{|c|}{ Education, yr } \\
\hline$\geq 10$ & 1 [ref] & 0 \\
\hline $7-9$ & $2.485(0.982-6.291)$ & 2 \\
\hline$<6$ & $3.599(1.453-8.913)$ & 3 \\
\hline \multicolumn{3}{|c|}{ Systolic blood pressure, $\mathrm{mm} \mathrm{Hg}$} \\
\hline$\leq 140$ & 1 [ref] & 0 \\
\hline$>140$ & $2.206(1.169-4.161)$ & 2 \\
\hline \multicolumn{3}{|c|}{ Body mass index, $\mathrm{kg} / \mathrm{m}^{2}$} \\
\hline$\leq 30$ & 1 [ref] & 0 \\
\hline$>30$ & $2.296(1.263-4.173)$ & 2 \\
\hline \multicolumn{3}{|c|}{ Total cholesterol, mmol/L } \\
\hline$\leq 6.5$ & 1 [ref] & 0 \\
\hline$>6.5$ & $1.879(1.012-3.491)$ & 2 \\
\hline \multicolumn{3}{|c|}{ Physical activity } \\
\hline Active & 1 [ref] & 0 \\
\hline Inactive & $1.693(0.953-3.009)$ & 1 \\
\hline
\end{tabular}

Note: $\mathrm{Cl}=$ confidence interval, ref = reference group.

*Adapted, with permission, from Kivipelto et al. ${ }^{46}$ Copyright $\odot 2006$ Elsevier. The original table included 2 predictive models. The model reproduced here does not include apolipoprotein $\mathrm{E} \varepsilon 4$ allele status, the inclusion of which did not increase the accuracy of the predictive model. 
blood pressure above $140 \mathrm{~mm} \mathrm{Hg}$ and a total serum cholesterol level less than $6.5 \mathrm{mmol} / \mathrm{L}$, his 20-year risk of dementia is less than $2 \%$. Investigators in the REVEAL study calculated risk curves using data from 12630 first-degree relatives of people with Alzheimer disease. ${ }^{47}$ Using this method, we can estimate that, by age 80 , Mr. A's risk will be about $\mathrm{I} 3 \%$, compared with $5 \%$ if he had no first-degree relative with Alzheimer disease. ${ }^{47}$

\section{Prevention of Alzheimer disease}

Epidemiologic studies have suggested that the consumption of several medications is associated with a reduced risk of dementia. These products include nonsteroidal anti-inflammatory drugs, ${ }^{17}$ vitamin supplements, ${ }^{48}$ and estrogens in women ${ }^{49}$ In the case of nonsteroidal anti-inflammatory drugs, the most recent meta-analysis, of 25 observational studies, concluded that the risk of all-cause dementia was significantly lower among study participants exposed to these drugs than among those who had not taken them..$^{18}$ However, a recently published randomized controlled trial of celecoxib (200 mg twice daily), naproxen (220 mg twice daily) and placebo in cognitively healthy participants was ended early because of concerns about drug safety and lack of effect, since no delay or reduction in the onset of dementia was observed. ${ }^{50}$ Thus, there is no justification for recommending the use of nonsteroidal anti-inflammatory drugs for the primary prevention of Alzheimer disease. Recent systematic reviews have also concluded that, in the absence of evidence from randomized controlled trials, there is no justification for consuming antioxidant vitamins $\mathrm{C}$ and $\mathrm{E}$ with the intention of reducing the risk of subsequent Alzheimer disease.${ }^{51}$ Furthermore, doses of vitamin $\mathrm{E}$ greater than $400 \mathrm{IU} / \mathrm{d}$ have been shown to have negative cardiovascular effects. ${ }^{52}$ Studies of $\mathrm{B}$ vitamins are inconclusive and are considered in a later article in this series.

Recommendations based on studies other than randomized controlled trials must be made with extreme caution. Estrogen hormone replacement therapy was widely recommended for the prevention of cardiovascular disease on the basis of casecontrol, epidemiologic and biological studies. Definitive, randomized controlled trials such as the Women's Health Initiative proved that the risks of myocardial infarction and stroke were actually increased with the use of such therapy. The Women's Health Initiative Memory Study, a large randomized controlled trial of estrogen and progesterone replacement therapy in over 7000 women aged 65-79 years, revealed that the

Table 4: Probability of dementia in late life according to the midlife risk scores*

\begin{tabular}{cc}
\hline Score $\dagger$ & Risk $(95 \% \mathrm{Cl}), \%$ \\
\hline $0-5$ & $1.0(0.0-2.0)$ \\
$6-7$ & $1.9(0.2-3.5)$ \\
$8-9$ & $4.2(1.9-6.4)$ \\
$10-11$ & $7.4(4.1-10.6)$ \\
$12-15$ & $16.4(9.7-23.1)$ \\
\hline
\end{tabular}

Note: $\mathrm{Cl}=$ confidence interval.

${ }^{*}$ Adapted, with permission, from Kivipelto et al. ${ }^{46}$ Copyright $\odot 2006$ Elsevier.

†Total scores are derived from individual scores for risk factors in Table 3. risk of dementia was increased with the use of estrogen either alone or in combination with progesterone. This finding effectively extinguishes recommendations for hormone replacement therapy for the prevention of dementia. ${ }^{53}$

\section{Knowledge gaps}

This review highlights significant gaps in our current knowledge of risk factors for Alzheimer disease. Although we now know much about individual risk factors for dementia, we do not know how they interact or which risk factors account for what proportion of dementia cases. Also lacking is a clear picture of which specific interventions can lower this risk, and at what age and in whom they need to be implemented. Large (and expensive) longitudinal intervention studies are needed to define the optimal preventive strategies. For primary prevention, treatment of hypertension offers the best chance of reducing or delaying the onset of dementia. It seems likely that lifestyle interventions (regular exercise, both physical and mental, moderate alcohol intake, and avoidance of tobacco and head injuries) may also reduce the risk of dementia. Because of the logistical challenges involved, it is unlikely that the present level of evidence, based on longitudinal cohort studies, will soon be superseded by randomized controlled trials to test these interventions. Given the very large numbers of healthy people who would need to participate in dementia prevention trials, attention has been increasingly focused on those at highest risk, especially those with mild cognitive impairment. Thus far, no pharmaceutical agents have been shown to delay or prevent conversion to dementia, although mentally stimulating activities are showing promise. Agents that interfere with the production of insoluble amyloid fragments in the brain, or accelerate their clearance, are being actively pursued. Despite previous disappointments, it is possible that a vaccine may eventually be found. With regard to genetic risk factors, new susceptibility genes for late-onset Alzheimer's disease continue to be found with increasing regularity.

\section{The case revisited}

Based on an empirical estimation from epidemiologic data, Mr. A's family physician can inform him that his risk of Alzheimer disease by the age of 80 is increased from $5 \%$ (baseline risk) to $13 \%$, because he has a first-degree relative with late-onset Alzheimer disease. ${ }^{47}$ Because nothing in Mr. A's family history suggests autosomal dominant multigenerational transmission, he does not require genetic testing. Mr. A should be advised to control his cardiovascular risk factors, including his hypertension and cholesterol levels, using evidence-based strategies. ${ }^{54,55}$ However, Mr. A cannot be assured that these interventions will decrease his risk of Alzheimer disease despite other proven health benefits. Other than those outlined in this article, there are no high-quality clinical trials that have evaluated the effectiveness of modifying risk factors, and there are no proven therapies that will prevent dementia.

This article has been peer reviewed.

Competing interests: None declared. 
Contributors: All of the authors contributed to the study conception and design, revised the manuscript critically for important intellectual content and approved the final version submitted for publication.

Acknowledgements: Christopher Patterson received support from the Institute of Advanced Studies, University of Bologna (Italy), during the preparation of this work. Chris MacKnight is supported by a New Investigator Award from the Canadian Institutes of Health Research.

Editor's Note: The background papers with supporting evidence for the recommendations from the Third Canadian Consensus Conference on the Diagnosis and Treatment of Dementia were published in the October 2007 issue of Alzheimer's and Dementia and are available at www.alzheimersanddementia.org. These articles are also freely available at www.cccdtd.ca (through agreement with Elsevier).

\section{REFERENCES}

I. Chertkow H. Diagnosis and treatment of dementia: Introduction. Introducing a series based on the Third Canadian Consensus Conference on the Diagnosis and Treatment of Dementia. CMAJ 2008;178:316-2I.

2. Patterson C, Feightner J, Garcia A, et al. General risk factors for dementia: a systematic evidence review. Alzheimers Dement 2007;3:34I-7.

3. Hsiung GYR, Sadovnick AD. Genetics and dementia: risk factors, diagnosis and management. Alzheimers Dement 2007;3:418-27.

4. Qiu C, von Strauss E, Fastbom J, et al. Low blood pressure and risk of dementia in the Kungsholmen Project. A 6-year follow-up study. Arch Neurol 2003;60:223-8.

5. Kivipelto M, Helkala E-L, Laakso MP, et al. Midlife vascular risk factors and Alzheimer's disease in later life: longitudinal, population based study. BMJ 200I; 322:1447-51.

6. Notkola I-L, Sulkava R, Pekkanen J, et al. Serum total cholesterol, apolipoprotein E $\varepsilon_{4}$ allele, and Alzheimer's disease. Neuroepidemiology ig98;17:I4-20.

7. Larrieu S, Letenneur L, Helmer C, et al. Nutritional factors and risk of incident dementia in the PAQUID longitudinal cohort. J Nutr Health Aging 2004;8:150-4.

8. Laurin D, Verreault R, Lindsay J, et al. Physical activity and risk of cognitive impairment and dementia in elderly persons. Arch Neurol 2001;58:498-504.

9. Podewils LJ, Guallar E, Kuller LH, et al. Physical activity, APOE genotype and dementia risk: findings from the Cardiovascular Health Cognition Study. Am J Epidemiol 2005; $16 \mathrm{I}: 639-5 \mathrm{I}$.

Io. Lindsay J, Laurin D, Verreault R, et al. Risk factors for Alzheimer's disease: a prospective analysis from the Canadian Study of Health and Aging. Am J Epidemiol 2002;156:445-53

II. Launer LJ, Andersen K, Dewey ME, et al.; EURODEM Incidence Research Group and Work Groups. Rates and risk factors for dementia and Alzheimer's disease. Results from EURODEM pooled analyses. Neurology I999;52:78-84.

I2. Almeida OP, Hulse GK, Lawrence D, et al. Smoking as a risk factor for Alzheimer's disease: contrasting evidence from a systematic review of case-control and cohor studies. Addiction 2002;97:15-28.

I3. Plassman BL, Havlik RJ, Steffens DC, et al. Documented head injury in early adulthood and risk of Alzheimer's disease and other dementias. Neurology 2000;55:II58-66.

I4. Kukull WA, Higdon R, Bowen JD, et al. Dementia and Alzheimer disease incidence: a prospective cohort study. Arch Neurol 2002;59:1737-46.

I5. Li G, Higdon R, Kukull WA, et al. Statin therapy and risk of dementia in the eld erly. A community-based prospective cohort study. Neurology 2004;63:1624-8.

I6. Zandi PP, Sparks DL, Khachaturian AS, et al; Cache County Study investigators. Do statins reduce risk of incident dementia and Alzheimer disease? The Cache County Study. Arch Gen Psychiatry 2005;62:217-24.

I7. Zandi PP, Anthony JC, Hayden KM, et al; Cache County Memory Study Investigators. Reduced incidence of AD with NSAID but not $\mathrm{H}_{2}$ receptor antagonists. The Cache County Study. Neurology 2002;59:880-6.

I8. De Craen AJM, Gussekloo J, Vrijsen B, et al. Meta-analysis of nonsteroidal antiinflammatory drug use and risk of dementia. Am J Epidemiol 2005;16r:II4-20.

I9. Campion D, Dumanchin C, Hannequin D, et al. Early-onset autosomal dominant Alzheimer disease: prevalence, genetic heterogeneity, and mutation spectrum. Am JHum Genet 1999;65:664-70.

20. Sleegers K, Roks G, Theuns J, et al. Familial clustering and genetic risk for dementia in a genetically isolated Dutch population. Brain 2004;I27:I64I-9.

2I. Schoenberg BS, Anderson DW, Haerer AF. Severe dementia. Prevalence and clinical features in a biracial US population. Arch Neurol I $985 ; 42: 740-3$

22. Haass C, Selkoe DJ. Soluble protein oligomers in neurodegeneration: lessons from the Alzheimer's amyloid beta-peptide. Nat Rev Mol Cell Biol 2007;8:IOI-I2.

23. GeneTests website. Available: www.genetests.org (accessed 2008 Jan 4).

24. Blennow K, de Leon MJ, Zetterberg H. Alzheimer's disease. Lancet 2006;368:387-403.

25. Rogaeva E, Meng Y, Lee JH, et al. The neuronal sortilin-related receptor SORL I is genetically associated with Alzheimer disease. Nat Genet 2007;39:168-77.

26. Lee JH, Cheng R, Schupf $\mathrm{N}$, et al. The association between genetic variants in SORLI and Alzheimer disease in an urban, multiethnic, community-based cohort. Arch Neurol 2007;64:50I-6.

27. Larner AJ, Doran M. Clinical phenotypic heterogeneity of Alzheimer's disease as- sociated with mutations of the presenilin-I gene. J Neurol 2006;253:139-58.

28. Cruts M, Van Broeckhoven C. Presenilin mutations in Alzheimer's disease. Hum Mutat I998;II:I83-90.

29. Sherrington R, Froelich S, Sorbi S, et al. Alzheimer's disease associated with mutations in presenilin 2 is rare and variably penetrant. Hum Mol Genet 1996;5:985-8.

30. Finckh U, Kuschel C, Anagnostouli M, et al. Novel mutations and repeated findings of mutations in familial Alzheimer disease. Neurogenetics 2005;6:85-9.

3I. Pericak-Vance MA, Grubber J, Bailey LR, et al. Identification of novel genes in lateonset Alzheimer's disease. Exp Gerontol 2000;35:1343-52.

32. Myers A, Wavrant De-Vrieze F, Holmans P, et al. Full genome screen for Alzheimer disease: stage II analysis. Am J Med Genet 2002;II4:235-44.

33. Blacker D, Bertram L, Saunders AJ, et al. Results of a high-resolution genome screen of 437 Alzheimer's disease families. Hum Mol Genet 2003;12:23-32.

34. Forette F, Seux ML, Staessen JA, et al. Prevention of dementia in randomized double-blind placebo-controlled Systolic Hypertension in Europe (Syst-Eur) trial. Lancet $1998 ; 352: 1347-51$

35. Folstein MF, Folstein SE, McHugh PR. Mini-Mental State." A practical method for grading the cognitive state of patients for the clinician. JPsychiatr Res I975;I2:I89-98.

36. Feigin V, Ratnasabapathy Y, Anderson C. Does blood pressure lowering treatment prevent dementia or cognitive decline in patients with cardiovascular and cerebrovascular disease? J Neurol Sci 2005;229-230:15I-5.

37. Shepherd J, Blauw GJ, Murphy MB, et al. Pravastatin in elderly individuals at risk of vascular disease (PROSPER): a randomized controlled trial. Lancet 2002;360:I623-30.

38. Heart Protection Study Collaborative Group. MRC/BHF Heart Protection Study of cholesterol lowering with simvastatin in 20536 high-risk individuals: a randomized placebo-controlled trial. Lancet 2002;360:7-22.

39. Scott HD, Laake K. Statins for the prevention of Alzheimer's disease [review]. Cochrane Database Syst Rev 200I; (4):CDoozi6o.

40. Kalmijn S, Launer LJ, Ott A, et al. Dietary fat intake and the risk of incident dementia in the Rotterdam Study. Ann Neurol 1997;42:776-82.

4I. Scarmeas N, Stern Y. Mayeux R, et al. Mediterranean diet, Alzheimer disease, and vascular mediation. Arch Neurol 2006;63:1709-I7

42. Wang H-X, Karp A, Winblad B, et al. Late-life engagement in social and leisure activities is associated with a decreased risk of dementia: a longitudinal study from the Kungsholmen Project. Am J Epidemiol 2002;155:108I-7.

43. Scarmeas N, Levy G, Tang M-X, et al. Influence of leisure activity on the incidence of Alzheimer's disease. Neurology 2001;57:2236-42.

44. Willis SL, Tennstedt SL, Marsiske M, et al. Long-term effects of cognitive training on everyday functional outcomes in older adults. JAMA 2006;296:2805-I4.

45. Tyas SL, Manfreda J, Strain LA, et al. Risk factors for Alzheimer's disease: a population-based, longitudinal study in Manitoba, Canada. Int J Epidemiol 2001;30:590-7.

46. Kivipelto M, Ngandu T, Laatikainen T, et al. Risk score for the prediction of dementia risk in 20 years among middle aged people: a longitudinal, populationbased study. Lancet Neurol 2006;5:735-4I.

47. Cupples LA, Farrer LA, Sadovnick AD, et al. Estimating risk curves for first-degree relatives of patients with Alzheimer's disease: The REVEAL study. Genet Med 2004;6:192-6.

48. Luchsinger JA, Mayeux R. Dietary factors and Alzheimer's disease. Lancet Neurol 2004;3:579-87.

49. LeBlanc ES, Janowsky J, Chan BKS, et al. Hormone replacement therapy and cognition. Systematic review and meta-analysis. JAMA 200I;285:I489-99.

50. ADAPT Research Group. Naproxen and celecoxib do not prevent AD in early results from a randomized controlled trial. Neurology 2007;68:180o-8.

5I. Boothby LA, Doering PL. Vitamin C and vitamin E for Alzheimer's disease. Ann Pharmacother 2005;39:2073-80.

52. Miller ER III, Pastor-Barriuso R, Dalal D, et al. Meta-analysis: high dosage vitamin $\mathrm{E}$ supplementation may increase all-cause mortality. Ann Intern Med 2005;142:37-46.

53. Shumaker SA, Legault C, Kuller L, et al. Conjugated equine estrogens and incidence of probable dementia and mild cognitive impairment in postmenopausal women: Women's Health Initiative Memory Study. JAMA 2004;291:2947-58.

54. Canadian Hypertension Education Program. Management and prevention of hypertension in Canada. 2007. Available: www.hypertension.ca/chep/ (accessed 2008 Jan 4)

55. Genest J, Frohlich J, Fodor G. et al, for the Working Group on Hypercholesterolemia and other Dyslipidemias. Recommendations for the management of dyslipidemia and the prevention of cardiovascular disease: summary of the 2003 update. $C M A J$ 2003;169:92I-4

Correspondence to: Dr. Christopher Patterson, Division of Geriatric Medicine, Chedoke Hospital, Hamilton Health Sciences, Sanatorium Rd., PO Box 2000, Hamilton ON L8N 3 Z5; pattec@hhsc.ca

\section{Articles to date in this series}

- Chertkow H. Diagnosis and treatment of dementia: Introduction. Introducing a series based on the Third Canadian Consensus Conference on the Diagnosis and Treatment of Dementia. CMAJ 2008;178:316-21. 